\title{
Fumarole Alteration of Hawaiian Basalts: A Potential Mars Analog
}

\author{
Teri L. Gerard and Lindsay J. McHenry \\ Department of Geosciences, University of Wisconsin-Milwaukee
}

\begin{abstract}
Over the last decade of Mars exploration, planetary scientists have discovered widespread sulfate-rich deposits indicating the acidic weathering of basalts (Squyres and Knoll, 2005; Bibring et al., 2006). By understanding the processes occurring during alteration of basalt in wet volcanic environments such as solfataras, we can learn more about the past aqueous processes on Mars. Chemically altered mineral assemblages of potentially hydrothermal origin have been detected at several Mars sites including Gusev Crater, Mawrth Vallis, and Nili Fossae (Ehlmann et al., 2010; Ehlmann et al., 2008; Chojnacki and Hynek, 2008; Schmidt et al., 2008; Yen et al., 2008; Bibring et al., 2006). The abundant magnesium and iron sulfates, hematite, and silica suggest alteration of basalts in water-limited, saline-acidic conditions, consistent with acidic evaporites or potentially sulfur-rich fumaroles (Squyres et al., 2007; Morris et al, 2000). In order to fully understand the formation of the minerals observed on Mars, it is necessary to fully understand the geochemical and mineralogical pathways that the basalt undergoes as it weathers under different conditions. Kilauea volcano Hawaii provides an excellent Mars analog for hydrothermal alteration. Samples collected at various fumaroles will be analyzed in order to determine any mineralogical and/or geochemical signatures that can help determine the origin of the mineral assemblages seen on Mars.
\end{abstract}

\section{Introduction}

Hawaii is a great place to study the alteration of basalts at solfataras since Kilauea volcano currently has active solfataras in contact with basalts, and since previous studies have identified mineral assemblages similar to those found on Mars (e.g. Morris et al., 2000). By collecting and geochemically and mineralogically analyzing rock samples from young fresh and altered basalts from the same units, it will be possible to determine the different mineral assemblages and element mobility patterns associated with this kind of alteration. These results will be applicable to the results of the Mars Exploration Rover (MER) missions and will serve as a terrestrial analog to help determine the origin of the sulfur-rich deposits seen on Mars. Determining the differences between volcanic and low-temperature aqueous alteration processes on Mars relates to NASA's strategic goal 3C.3 and MEPAG (2008) goal 1A of assessing the past and present habitability of Mars.

Hawaii has been identified as a useful Mars analog site since its ocean island type basalts are more similar in composition to Martian basalts than most other Earth basalts and since the basalts are weathering in a variety of environments, resulting in alteration minerals that are seen on Mars (Schiffman et al., 2006; Seelos et al., 2010). Fumaroles are currently found in and near the Kilauea and $\mathrm{Pu}^{\prime} \mathrm{u}$ ' $\overline{\mathrm{O}}^{`} \overline{\mathrm{o}}$ calderas, and steam vents are additionally located at Kilauea Iki, Mauna Ulu, and other more recent vents and lava flows. Recent (and current) fumarole deposits are located on the wetter, northeastern side of the volcano (i.e. Sulfur Banks) and the drier, southwestern side (i.e. Ka'u Desert). Rock samples from young fresh and altered basalts from different fumarolic environments were collected in order to determine the mineral assemblages 
and element mobility patterns associated with this kind of alteration. The results will serve as a terrestrial analog to help determine the origin of the sulfur-rich deposits seen on Mars and will also be compared to previous studies on fumarole alteration in other contexts, including the rhyolites, dacites, and andesites of the Valley of Ten Thousand Smokes, Alaska and previous studies at Kilauea (Papike et al., 1991a, b; Papike, 1992; Morris et al., 2000).

\section{Background}

Hydrothermal systems on Mars. Mars was volcanically active for much of its history and it is believed to have widespread past aqueous activity (Hynek and Phillips, 2003; Bibring et al., 2006), which likely included hydrothermal environments. Hydrothermal environments could have provided a suitable environment for microbial life (Walter and Des Marais, 1993). Current models for Mars suggest that there was extensive volcanism early in Mars' history with warmer, wetter conditions which is shown by the clays seen by OMEGA (Bibring et al., 2005, 2006). As volcanism slowed down and Mars became colder, more arid, and acidic, sulfates formed (Bibring et al., 2005, 2006). Hydrothermal environments likely remained active during this time.

Hydrothermal environments can be identified by the alteration products and geochemical signatures formed by the interaction of fluids with basalt. Many mineralogical features seen by the MERs could have resulted from either low-temperature aqueous alteration or hydrothermal alteration (McCollom and Hynek, 2005). Further constraining the mineralogical and geochemical pathways of hydrothermal alteration will allow us to more accurately reconstruct the aqueous history of Mars.

Previous Hawaiian studies. Previous studies at Kilauea volcano have explored both high and low temperature weathering of basalt, alteration of basalt in an "acid fog" environment, and recent solfatara activity (Morris et al., 2000; Schiffman et al., 2000; Schiffman et al., 2006; Minitti et al., 2007; Chemtob et al., 2010; Seelos et al., 2010). In particular, Chemtob et al., (2010) and Seelos et al. (2010) examined the mineralogy of basalts in the vicinity of recent solfataras on the 1974 and 1976 lava flows in the Ka'u Desert. They did not look at the preservation of alteration materials at older solfataras, or the spatial changes in mineralogy. Studies such as Morris et al. (2000) examined only the alteration materials at the fumarole (at Sulfur Banks) and did not sample fresh, unaltered basalt. Most of the previous studies employed VNIR spectroscopy rather than X-ray Diffraction (XRD), X-ray Fluorescence (XRF), or Electron Probe Microanalysis (EPMA).

\section{Methods}

We collected samples from Kilauea Volcano, Hawaii in December 2011. Rock and mineral samples were collected at and near the rim of $\mathrm{Pu}^{\prime} \mathrm{u}{ }^{\prime} \overline{\mathrm{O}}^{`} \overline{\mathrm{o}}$ at the Thanksgiving Eve Breakout flow, the drill hole at Sulfur Banks, Kilauea Iki, Mauna Ulu, and the Kula Kai Caverns. Fresh and altered lavas and the associated mineral coatings were collected near active fumaroles. The steam and gases emitted from the fumaroles ranged from just above ambient temperature to $130^{\circ} \mathrm{C}$. Some of the samples were analyzed in the field with a TERRA portable XRD in order to identify any ephemeral minerals that might not survive transport. In the laboratory, the samples were analyzed by XRD by crushing the samples in a micronizing mill to a fine powder and drying overnight. 1 gram of the powder was then mounted and analyzed with a Bruker D8 Focus XRD. This provided the mineral assemblages of the samples. XRF was also used, providing major and 
trace element data. Samples were crushed in a micronizing mill to a fine powder and loss on ignition was determined using $\sim 1 \mathrm{~g}$ for each sample. A second $1.000 \mathrm{~g}$ of sample was combined with $\sim 1 \mathrm{~g}$ of ammonium nitrate and 10.000 $\mathrm{g}$ of Claisse 50:50 LiT:LiM flux with an integrated $\mathrm{LiBr}$ non-wetting agent, mixed thoroughly, and fused into a homogenous glass bead in a Claisse M4 fluxer for XRF analysis with a Bruker S4 Pioneer Sequential Wavelength Dispersive XRF Spectrometer. For a more detailed description of the methods, see McHenry, (2009).

Dr. Brian Hynek collected several gas and gas condensate samples from the vents for a preliminary microbiology study to help assess the habitability of this extreme environment. Crust and sediment samples congruent with gas and mineral samples were collected aseptically and stored frozen until analysis. Hynek is currently analyzing the gas and gas condensates samples collected.

\section{Results}

Sulfates and phosphates were the most commonly detected alteration minerals. Halides, clays, and zeolites were also present. Several minerals were only seen in the freshest samples from $\mathrm{Pu}^{\prime} \mathrm{u}{ }^{\prime} \overline{\mathrm{O}}^{`} \overline{\mathrm{o}}$ indicating that there is a temporal element to the preservation of these minerals. There is also a spatial element with more secondary alteration minerals detected closest to the vent.

At Sulfur Banks, elemental sulfur and gypsum are by far the most common minerals seen. Sulfur and phosphates are most commonly located closest to the vent and gypsum and oxides are located the furthest from the vent. The most heavily altered sample of basalt contained the smectite clay montmorillonite and the sulfate natrojarosite, both minerals seen on Mars (Figure 1). The minerals identified at $\mathrm{Pu}^{\prime} u$ ' $\mathrm{O}^{`} \bar{o}$ are mostly sulfates such as gypsum, anhydrite, and mirabilite. Several of the sulfates were only found at $\mathrm{Pu}^{6} \mathrm{u}$ ' $\overline{\mathrm{O}}^{`} \overline{\mathrm{o}}$ likely due to the fact that they quickly alter over time. The samples from Mauna Ulu were heavily altered with the most common alteration mineral found being halides, such as ralstonite. Calcite, phosphates, and sulfates were found in the lava tube caves at Kalakai Caves. Precipitated gypsum is the main secondary mineral at Kilauea Iki and appears closest to the vent. For example, KI 11-6 (Figure 2) collected at the vent, shows gypsum along with the basaltic minerals augite and KI 11-10 (Figure 3) collected from $\sim 10.5 \mathrm{~m}$ away from the vent shows a mostly unaltered basalt. Preliminary results from the first field season indicate the presence of minerals seen on Mars confirming the suitability of this area as a Mars analog. Further analysis will enable us to identify which minerals are best suited to be a hydrothermal signature. 


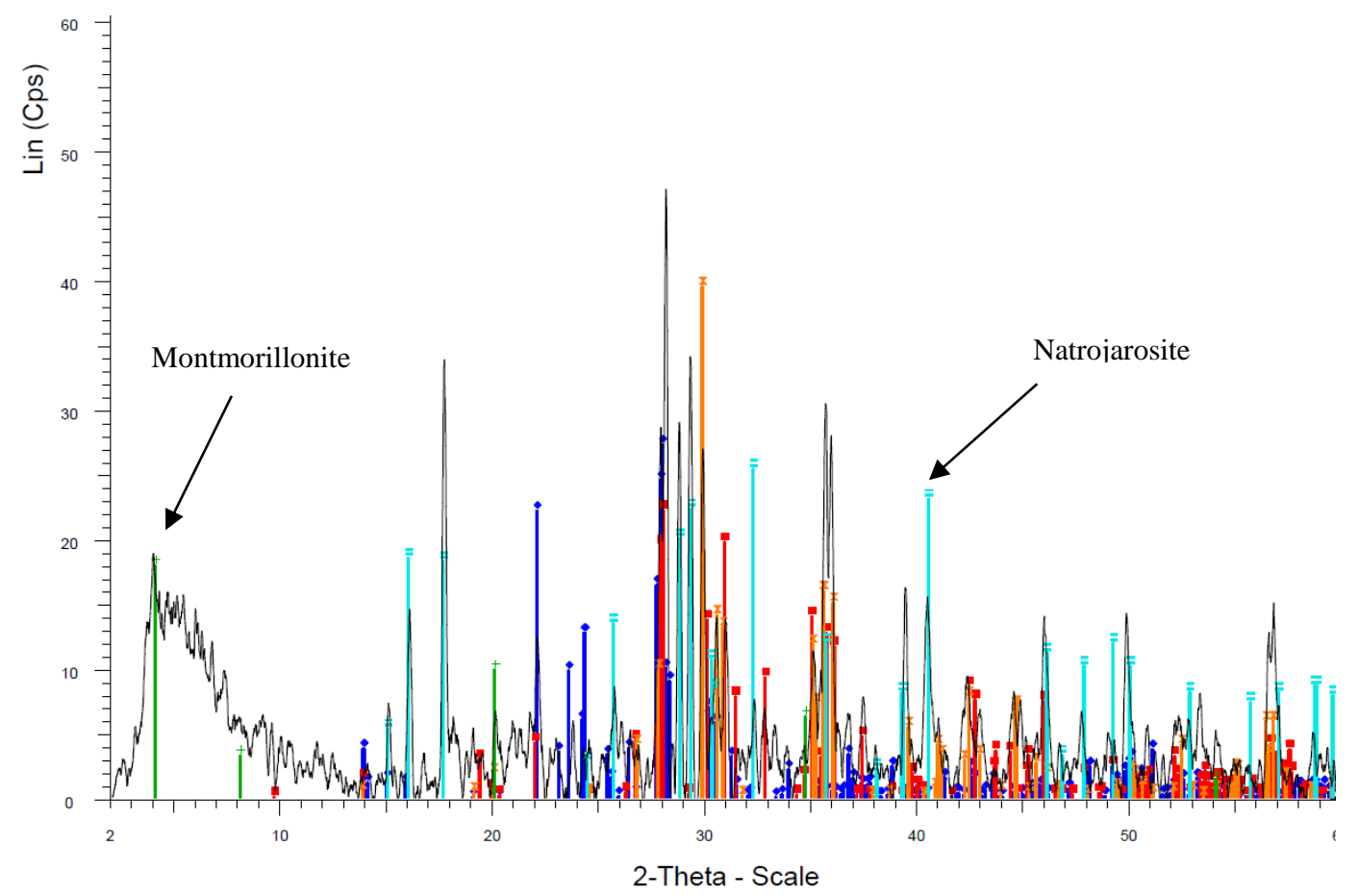

Figure 1: XRD spectrograph of sample SB 11-5 from Sulfur Banks. Montmorillonite, a smectite clay, and natrojarosite, a sulfate, are identified. These minerals have been seen on Mars.

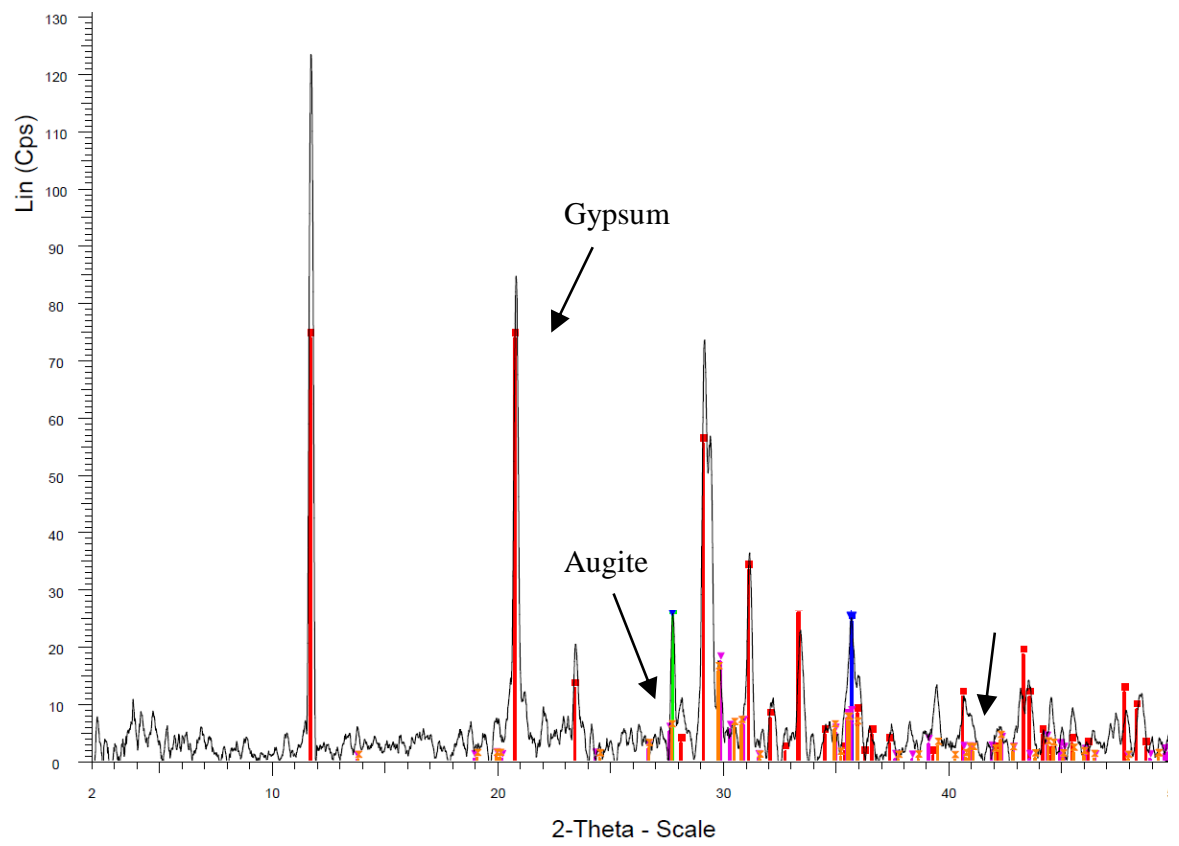

Figure 2: Sample KI 11-6 was collected at the vent. The XRD spectrum shows gypsum along with the basaltic mineral augite. 


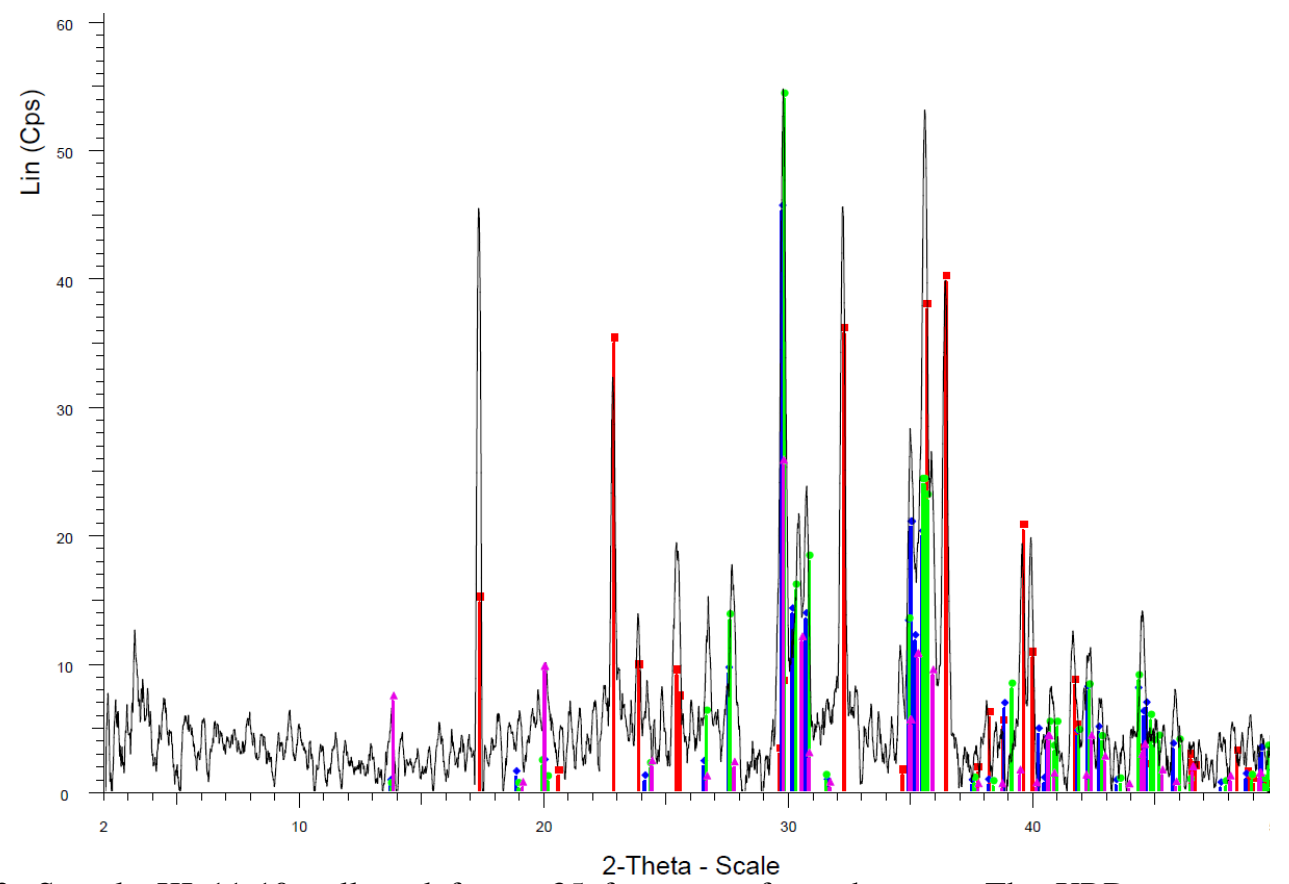

Figure 3: Sample KI 11-10 collected from $\sim 35$ feet away from the vent. The XRD spectrum shows minerals commonly found in basalt such as fosterite and clinopyroxene.

\section{Future Work}

We will continue to analyze samples from the 2011 field season using a variety of techniques. Scanning Electron Microscopy (SEM) will provide the mineral assemblages and imaging of the fine-grained alteration minerals and textures. The thin alteration coatings will be analyzed by EPMA to determine their elemental composition (methods of Minitti et al., 2007). Selected samples will be sent to U. Arkansas for spectral analysis by Visible-Near Infrared (VNIR) in order to determine early alteration phases that are not detectable by XRD such as palagonite, amorphous silica, or nanophase Fe oxides.

This pilot study concentrated on determining the mineral assemblages and geochemical changes during alteration of young basalt at active fumaroles and steam vents. We are planning a second trip to Kilauea for late 2012 in which we hope to collect rock and mineral samples from several "fossil" fumaroles such as those in the Ka'u Desert. This will provide a temporal component to the study, allowing us to see what mineralogical and geochemical features of fumarole-driven basalt alteration are preserved in the rock record, and thus what signatures are most useful in trying to identify more ancient deposits. We will collect a transect of rock and mineral samples to determine the spatial pattern of the geochemical alteration. It will be important to collect samples of both the freshest, most unaltered basalt and the corresponding fumarolic altered basalts in order to model the geochemical pathways involved in the alteration processes such as leaching. The samples will be analyzed by XRD, XRF, SEM, and EPMA. By comparing currently active fumaroles to older fumaroles, I will be able to determine what mineralogical and geochemical features of fumarole-driven basalt alteration are preserved in the rock record, and thus what signatures are most useful in trying to identify more ancient deposits of volcanic/hydrothermal activity. By comparing the mineral assemblages of fumaroles from a wet environment (sites from 2011) and dry environment (sites from 2012), it will be possible to determine the differences in weathering pathways and products. 


\section{Conclusions}

Mineral samples were collected at several active fumaroles at Kilauea volcano. Preliminary analysis indicates the presence of some of the same minerals, such as sulfates, that have been seen on Mars. Further analysis will enable the determination of the mineralogical and geochemical pathways involved in solfatara-related alteration of basalt. A second field expedition will enable us to collect samples from older, extinct fumaroles in order to determine how long the mineralogical and geochemical changes are likely to be preserved. This will lead to a better understanding of the water-limited, acid-sulfate weathering history of Mars, in particular the sulfate-bearing Gusev Crater soils and bedrock where sulfur-rich hydrothermal processes are believed to have been involved (Squyres et al., 2007) and Meridiani Planum deposits, where acid-sulfate evaporitic conditions are generally preferred (Squyres et al., 2009).

\section{References}

Bibring, J.-P. et al., 2005. Mars surface diversity as revealed by the OMEGA/Mars Express observations. Science 307, 1576-1581.

Bibring, J.-P. et al., 2006. Global mineralogical and aqueous Mars history derived from OMEGA/Mars Express data. Science 312, 400-404.

Bibring, J.-P. et al., 2007. Coupled ferric oxides and sulfates on the Martian surface. Science $317,1206-1210$

Chemtob, S.M., Jolliff, B.L., Rossman, G.R., Eiler, J.M., Arvidson, R.E., 2010. Silica coatings in the Ka'u Desert, Hawaii, a Mars analog terrain: a micromorphological, spectral, chemical, and isotopic study. JGR 115, E04001.

Chojnacki, M., Hynek, B., 2008. Geological context of water-altered minerals in Valles Marineris, Mars. JGR 113, E12005.

Ehlmann, B.L., Mustard, J.F., Fassett, C.I., Schon, S.C., Head, J.W. III, des Marais, D.J., Grant, J.A., Murchis, S.L., 2008. Clay minerals in delta deposits and organic preservation potential on Mars. Nature, vol. 1, pp. 355-358.

Ehlmann, B.L., Mustard J.F., Bish, D.L., 2010. Weathering and hydrothermal alteration of basalts in Iceland: Mineralogy from VNIR, TIR, XRD, and implications for linking Mars orbital and surface datasets. Abstract. Lunar and Planetary Science Conference, 2010.

Hynek, B.M., Phillips, R.J., 2003. New data reveal mature, integrated drainage systems on Mars indicative of past precipitation. Geology 31, 757-760.

McCollom, T.M., Hynek, B.M., 2005. A volcanic environment for bedrock diagenesis at Meridiani Planum on Mars. Nature 438, 1129-1131.

McHenry, L.J. 2009. Element mobility during zeolitic and argillic alteration of volcanic ash in a closed-basin lacustrine environment: Case study Olduvai Gorge, Tanzania. Chemical Geology 265: 540-552. 
Minitti, M.E., Weitz, C.M., Lane, M.D., Bishop, J.L., 2007. Morphology, chemistry, and spectral properties of Hawaiian rock coatings and implications for Mars. JGR 112, E05015.

Morris, R.V. et al., 2000. Mineralogy, composition, and alteration of Mars Pathfinder rocks and soils: Evidence from multispectral, elemental, and magnetic data on terrestrial analogue, SNC meteorite, and Pathfinder samples. JGR 105, 1757-1817.

Papike, J.J., Keith, T.E.C., Spilde, M.N., Shearer, C.K., Galbreath, K.C., and Laul, J.C., 1991a. Major and trace element mass flux in fumarolic deposits, Valley of Ten Thousand Smokes, Alaska: Rhyolite-rich protolith. Geophysical Research Letters vol. 18 no. 8., pp. 1545-1548.

Papike, J.J., Keith, T.E.C., Spilde, M.N., Galbreath, K.C., Shearer, C.K., and Laul, J.C., $1991 b$. Geochemistry and mineralogy of fumarolic deposits, Valley of Ten Thousand Smokes, Alaska: Bulk chemical and mineralogical evolution of dacite-rich protolith. American Mineralogist, vol. 76, pp. 1662-1673.

Papike, J.J., 1992. The Valley of Ten Thousand Smokes, Katmai, Alaska: A unique geochemistry laboratory. Geochimica et Cosmochimica Acta, vol. 56, pp. 1429-1449.

Schiffman, P., Spero, H.J., Southard, R.J., Swanson, D.A., 2000. Controls on palagonitization versus pedogenic weathering of basaltic tephra: Evidence from the consolidation and geochemistry of the Keanakako'i Ash Member, Kilauea Volcano. G3 1, 1040.

Schiffman, P., Zierenberg, R., Marks, N., Bishop, J.L., Dyar, M.D., 2006. Acid-fog deposition at Kilauea volcano: A possible mechanism for the formation of siliceous-sulfate rock coatings on Mars. Geology 34, 921-924.

Schmidt, M.E. et al., 2008. Hydrothermal origin of halogens at Home Plate, Gusev Crater. JGR 113, E06S12.

Seelos, K.D. et al., 2010. Silica in a Mars analog environment: Ka'u Desert, Kilauea Volcano, Hawaii. JGR 115, E00D15.

Squyres, S. et al., 2007. Pyroclastic activity at Home Plate in Gusev Crater, Mars. Science 316, 738-742.

Squyres, S. et al., 2009. Exploration of Victoria Crater by the Mars rover Opportunity. Science 324, 1058-1061.

Squyres, S., Knoll, A., 2005. Sedimentary rocks at Meridiani Planum: Origin, diagenesis, and implications for life on Mars. EPSL 240, 1-10.

Walter, M.R., Des Marais, D.J., 1993. Preservation of biological information in thermal spring deposits: developing a strategy for the search for fossil life on Mars. Icarus 101, 129-143. 
Yen, A.S. et al., 2008. Hydrothermal processes at Gusev Crater: An evaluation of Paso Robles class soils. JGR 113, E06S10. 